\section{REVIEW ARTICLE}

A. Patsalides

J. Knopman

A. Santillan

A.J. Tsiouris

H. Riina

Y.P. Gobin

\title{
Endovascular Treatment of Spinal Arteriovenous Lesions: Beyond the Dural Fistula
}

SUMMARY: During the past few decades, there have been significant advances in the understanding of spinal vascular lesions, mainly because of the evolution of imaging technology and selective spinal angiography techniques. In this article, we discuss the classification, pathophysiology, and clinical manifestations of spinal vascular lesions other than DAVFs and provide a review of the endovascular approach to treat these lesions.

ABBREVIATIONS: $\mathrm{ASA}=$ anterior spinal artery; $\mathrm{AVF}=$ arteriovenous fistula; $\mathrm{AVM}=$ arteriovenous malformation; DAVF = dural arteriovenous fistula; MMA = middle meningeal artery; $n$-BCA = n-butyl 2-cyanoacrylate; PSA = posterior spinal artery; PVA = polyvinyl alcohol; $\mathrm{SAH}=$ subarachnoid hemorrhage; SVM = spinal vascular malformation

S pinal arteriovenous lesions are rare entities, with severe consequences if untreated. During the past few decades, there have been significant advances in the understanding of these lesions, mainly because of selective spinal angiography. Increased knowledge of the angioarchitecture and pathophysiology of SVMs has lead to the development of endovascular embolization for these lesions, first described by Dr Djindjian in France and Drs DiChiro and Doppman in the United States. Further evolution in imaging technology and interventional and surgical techniques allows us to manage these lesions more efficiently, in the context of a multidisciplinary approach. In this article, we present the classification and pathophysiology of spinal arteriovenous lesions and the approach to endovascular treatment. This article does not discuss the pathophysiology and management of spinal DAVFs, which was discussed in a prior review article in this journal. ${ }^{1}$

\section{Classification}

Spinal arteriovenous lesions represent a group of diverse diseases with variable taxonomy. Early classification was purely descriptive and based on histology, without the necessary understanding of the pathophysiology of each different entity. With the evolution of spinal angiography, our ability to examine the angioarchitecture of these lesions has improved significantly and has led to more accurate classification systems based on topographic and anatomic criteria. However, despite the advancements in the classification of SVMs, there is still an element of subjective judgment, and some lesions will defy any classification system. Based on hemodynamic criteria, there are 2 distinct categories: 1 ) the spinal AVFs with a direct shunt between the artery and vein, and 2) the AVMs with the presence of a nidus (a network of abnormal vessels) between the artery and vein (Table). ${ }^{2}$ Capillary telangiectasias and cavern-

From the Division of Interventional Neuroradiology, Departments of Radiology and Neurosurgery (A.P., J.K., A.S., H.R., Y.P.G), and Department of Radiology (A.J.T.), New York Presbyterian Hospital/Weill Cornell Medical College, New York, New York.

Please address correspondence to Athos Patsalides, MD, MPH, Division of Interventional Neuroradiology, Departments of Neurosurgery and Radiology, New York Presbyterian Hospital/Weill Cornell Medical College, 525 E 68th St, Box 99, New York, NY 10065; e-mail: atp9002@med.cornell.edu

Indicates open access to non-subscribers at www.ajnr.org

DOI 10.3174/ajnr.A2190

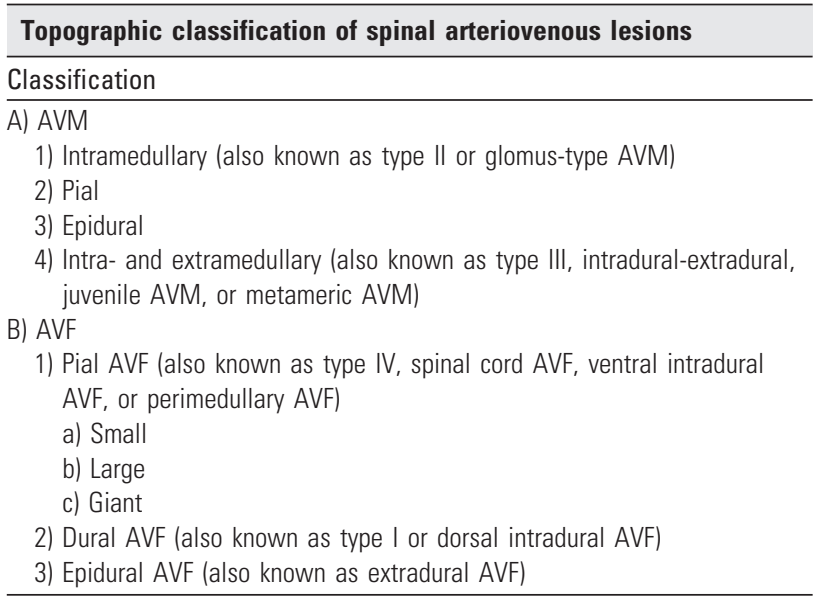

ous hemangiomas are vascular malformations without arteriovenous shunt surgery and are not amenable to endovascular therapy. ${ }^{3}$

\section{Pathophysiology of Spinal Arteriovenous Lesions}

Spinal arteriovenous lesions may be associated with myelopathy (sensory and motor deficits, bladder and bowel dysfunction), radicular pain or deficit, back pain, or spinal column deformity. Hemorrhage, venous hypertension, arterial steal, and mass effect are the possible mechanisms for spinal cord damage, and their importance varies for each type of lesion. Hemorrhage can occur in the cord parenchyma and/or subarachnoid space, leading to acute onset of neurologic deficits. The risk of hemorrhage is greater in spinal cord AVMs. Large and giant spinal cord AVFs, cervical DAVFs, and intracranial DAVFs with perimedullary venous drainage may also present with hemorrhage, whereas small spinal cord AVFs and thoracic and lumbar DAVFs are less likely to bleed. ${ }^{4,5}$ Spinal artery and intranidal aneurysms are associated with a high risk for hemorrhage. ${ }^{6}$ Rarely, spinal AVMs with intracranial venous drainage may lead to intracranial hemorrhage. ${ }^{7}$ Venous hypertension is typically associated with arteriovenous lesions with perimedullary venous drainage.

The classic lesion associated with venous hypertension is the spinal DAVF, but this phenomenon can be seen with any lesion that has perimedullary venous drainage, such as the pial AVF of the spinal cord or certain intracranial dural AVFs. The 
pressure in the perimedullary veins is abnormally increased due to the direct arteriovenous shunt, and this increased pressure is transmitted to the intrinsic veins of the cord due to the lack of valves, resulting in "arterialization" of these veins, with thickened and tortuous walls, decreased intramedullary arteriovenous pressure gradient, decreased tissue perfusion, and hypoxia of the spinal cord. ${ }^{8}$ In addition, loss of autoregulation of the intrinsic cord vessels leads to cord edema and disruption of the blood-cord barrier. ${ }^{9}$ Because the conus is the lowest part of the spine in the upright position, venous hypertension usually predominates there, aided by a valveless venous system. The pressure in the draining veins varies with arterial pressure, resulting in exacerbated symptoms during exercise. Venous hypertension can be confirmed with angiography of the artery of Adamkiewicz by demonstrating severe prolongation of the venous phase. ${ }^{10}$ Lesions with high-flow arteriovenous shunts may lead to steal of arterial blood from adjacent normal spinal cord tissue. ${ }^{11}$ Lesions in the dorsal aspect of the cord that are fed by the ASA are also prone to arterial steal because of the low potential for collateral arterial supply to the normal cord tissue. Mass effect is a rare mechanism for myelopathy. Large aneurysms ${ }^{12}$ and large dilated veins/varices like the ones seen with giant spinal cord AVFs may compress the spinal cord or nerve roots.

\section{Clinical Manifestations}

\section{Spinal Cord AVMs}

Spinal cord AVMs represent 20\%-30\% of SVMs. ${ }^{2}$ They are high-flow lesions supplied by $\geq 1$ branch of the ASA and/or PSA with a discrete nidus. Analogous to brain AVMs, they represent a focal network of arteriovenous shunts that drain into the spinal veins. Associated aneurysms of the feeding arteries and the nidus are common. ${ }^{6}$

Spinal cord AVMs are evenly distributed along the spinal cord axis and may be located within the parenchyma (intramedullary) (Fig 1), the surface of the spinal cord (pial) (Fig 2), the epidural space (epidural) (Fig 3), or they may have a more complex anatomy with both intramedullary and extramedullary components without respect to tissue boundaries. The conus medullaris $\mathrm{AVM}^{13}$ represents a distinct type located on the conus medullaris or cauda equina and can extend along the filum terminale.

Spinal cord AVMs typically appear in childhood or early adulthood, with sudden onset of symptoms due to hemorrhage or compression-induced myelopathy. Patients may present with motor and/or sensory deficits, bladder and bowel disturbances, and pain. Most patients have partial improvement after the initial event, but new events are likely and result in progressive deterioration of spinal cord function. Arterial steal and venous hypertension may occur and, though less common, can result in progressive myelopathy. Conus medullaris AVMs frequently produce radiculopathy and myelopathy at the same time. ${ }^{13}$

\section{Pial AVF}

The pial AVF (Fig 4) is characterized by a single or a few intradural direct arteriovenous shunts without an intervening nidus. It is usually located on the pial surface of the cord. Arterial supply originates from $\geq 1$ arterial feeder from the ASA or
PSA, and the shunt drains into the spinal cord veins. The pial AVFs are subdivided into small (type I), large (type II), and giant (type III), according to the size and flow of the direct shunt. ${ }^{14}$ Small AVFs correspond to a single slow-flow shunt between a nondilated ASA and a slightly dilated spinal vein and are located in the anterior aspect of the conus medullaris or the filum terminale. Small spinal cord AVFs of the conus medullaris can easily be confused with DAVFs.

Large AVFs correspond to a single or a few shunts, with greater flow than the small AVFs and ampullary dilation of the draining vein. They are usually located in the posterolateral aspect of the conus medullaris and are supplied by $\geq 1$ mildly dilated feeder from the PSA. Large AVFs can also occur anteriorly, in which case the feeder is a branch of the ASA. Regardless of the location, large AVFs have many arterial feeders that converge to 1 or a few shunts. Giant AVFs have a single or a few high-flow shunts with $\geq 1$ dilated arterial feeder from the ASA and the PSA. The arterial feeders converge to a single shunt draining into massively dilated arterialized draining veins. Giant AVFs are more prevalent in the conus medullaris region and can be associated with complex vascular malformation syndromes. ${ }^{15}$ They can also be seen in the cervical and thoracic levels of the spinal cord.

The large and giant spinal cord AVFs usually present in childhood and adolescence with a variety of clinical scenarios. Acute onset of symptoms can occur secondary to SAH, while progressive motor and sensory deterioration and sphincter disturbance usually result from vascular steal, venous hypertension, or mass effect on the spinal cord and/or nerve roots from the dilated veins. SAHs usually occur from venous rupture. ${ }^{16}$ The mass effect on the cord or nerve roots from dilated veins explains the sometimes asymmetric nature of deficits.

Small spinal cord AVFs present later in life, with progressive neurologic deficits related to venous hypertension, while $\mathrm{SAH}$ is rare. Hematomyelia has also been observed after rupture of the anterior spinal vein, which is subpial in location. ${ }^{17}$

For all these lesions, spinal angiography is essential to establish the diagnosis, characterize the shunt, and decide the treatment approach.

\section{Epidural AVF}

The epidural AVF (Fig 5) is a rare lesion associated with significant neurologic morbidity. It represents an abnormal shunt between an artery and an epidural vein/venous plexus. Neurologic symptoms occur by mass effect on the spinal cord and/or nerve roots from the enlarged draining veins, arterial steal if there is diversion of a large quantity of blood from the ASA, and/or by venous hypertension if the shunt drains though spinal veins causing resistance to venous outflow. Epidural AVFs are primarily described in case reports and small case series, ${ }^{18-20}$ with the cervical spine representing the most common location. ${ }^{21}$ The arterial feeders that supply the epidural AVF are usually branches of the costocervical and thyrocervical trunk; the vertebral, intercostal, and lumbar arteries; and arteries that supply the sacrum and the pelvis. Therapeutic options include surgery and embolization, with the latter the treatment of choice, provided the shunt and the proximal draining vein can be occluded. ${ }^{22}$ Liquid embolic materials are the agents of choice. The transvenous approach can also be used in cases of incomplete transarterial embolization 

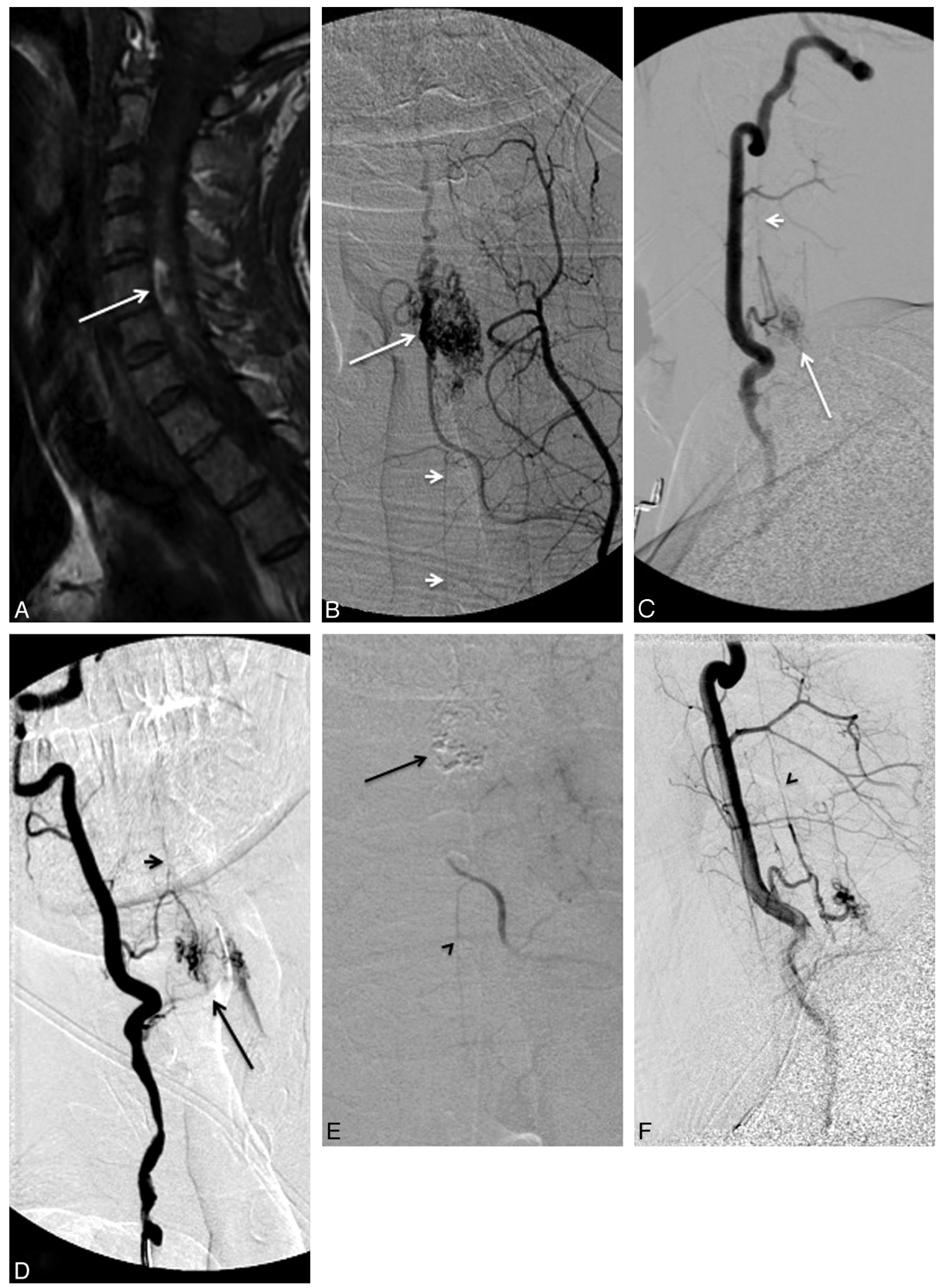

Fig 1. $A, A$ 31-year-old patient presenting with quadriparesis secondary to intramedullary hemorrhage seen as hyperintensity in a sagittal T1-weighted MR image (arrow). $B-D$, The spinal angiograms show an intramedullary AVM (arrow) with arterial feeders from the ASA (arrowheads), which, at this level, is supplied by the right vertebral artery (C and D) and the left ascending cervical artery from the thyrocervical trunk $(B)$. E, The AVM is embolized with $n$-BCA (arrow) with a microcatheter positioned via the left ascending cervical artery into the ASA branch feeding the nidus. Postembolization angiogram shows no residual supply to the nidus from the left ascending cervical artery, while the supply to the ASA is preserved (arrowhead). F, Postembolization right vertebral artery angiogram shows residual nidus $(<30 \%$ of the total AVM nidus) and preserved flow into the ASA (arrowhead). 

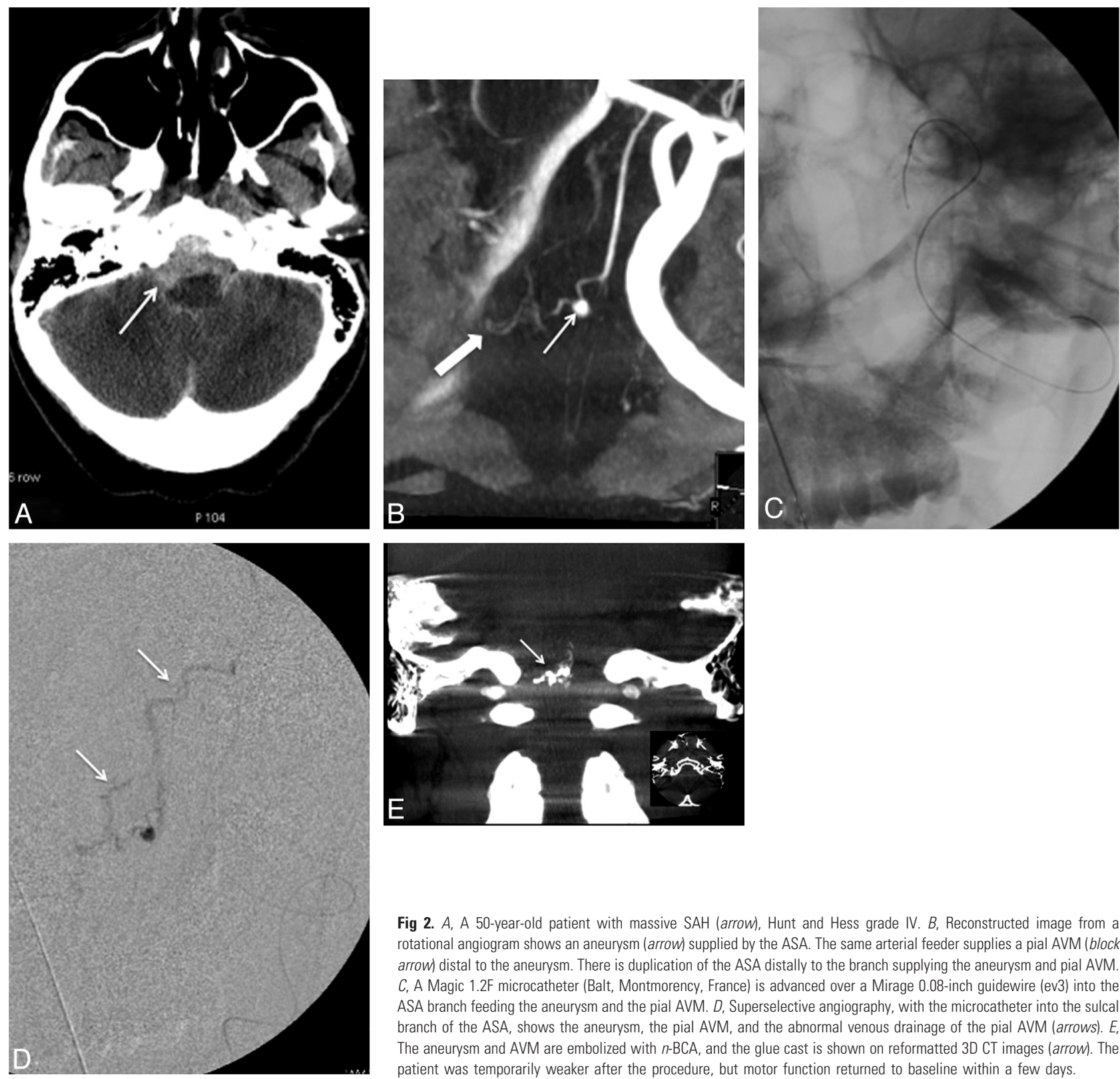

Fig 2. A, A 50-year-old patient with massive SAH (arrow), Hunt and Hess grade IV. B, Reconstructed image from a rotational angiogram shows an aneurysm (arrow) supplied by the ASA. The same arterial feeder supplies a pial AVM (block arrow) distal to the aneurysm. There is duplication of the ASA distally to the branch supplying the aneurysm and pial AVM C. A Magic 1.2F microcatheter (Balt, Montmorency, France) is advanced over a Mirage 0.08-inch guidewire (ev3) into the ASA branch feeding the aneurysm and the pial AVM. D, Superselective angiography, with the microcatheter into the sulcal branch of the ASA, shows the aneurysm, the pial AVM, and the abnormal venous drainage of the pial AVM (arrows). E, The aneurysm and AVM are embolized with $n-\mathrm{BCA}$, and the glue cast is shown on reformatted 3D CT images (arrow). The patient was temporarily weaker after the procedure, but motor function returned to baseline within a few days.

and when the cord is not draining through the vein to be occluded. ${ }^{23,24}$

\section{Intramedullary-Extramedullary AVM and Complex Angiomatosis}

Intramedullary-extramedullary or intradural-extradural AVMs are extremely rare lesions that correspond to complex AVMs extending along a discrete somite level and involving $>1$ structure of spinal cord, dura, vertebrae, paravertebral soft tissues, or skin. Complete involvement of an AVM along a somite level has been described in Cobb syndrome, but the incomplete types are more common. Diffuse angiomatosis, such as Rendu-Osler-Weber disease, may be seen in association with spinal cord AVMs. ${ }^{25-27}$ Intramedullaryextramedullary AVMs are typically seen in children and young adults and present with pain and progressive myelopathy secondary to mass effect, hemorrhage, and arterial steal. Multiple feeders over several vertebral levels are common.

\section{Intracranial DAVF with Spinal Perimedullary}

\section{Venous Drainage}

The intracranial DAVF with perimedullary and spinal venous drainage (Fig 6) — classified as type $\mathrm{V}$ in the Djindjian-Merland classification ${ }^{28}$-represents a distinct category of intracranial lesions with spinal cord symptoms. These lesions receive arterial supply from meningeal branches of the internal carotid, external carotid, and the vertebral arteries, with venous drainage around the brain stem and into the pial veins in the anterior and posterior surface of the spinal cord. They are usually seen in men in their third-to-seventh decades of life, and because of the venous drainage pattern, they may cause venous hypertension of the spinal cord. The typical clinical findings include ascending myelopathy, sphincter disturbances, bulbar signs like difficulty swallowing, and autonomic dysfunction. ${ }^{29}$ These lesions highlight the importance of complete and meticulous angiographic evaluation from the cranium to the sacrum in cases of venous hypertension of the spinal cord. 

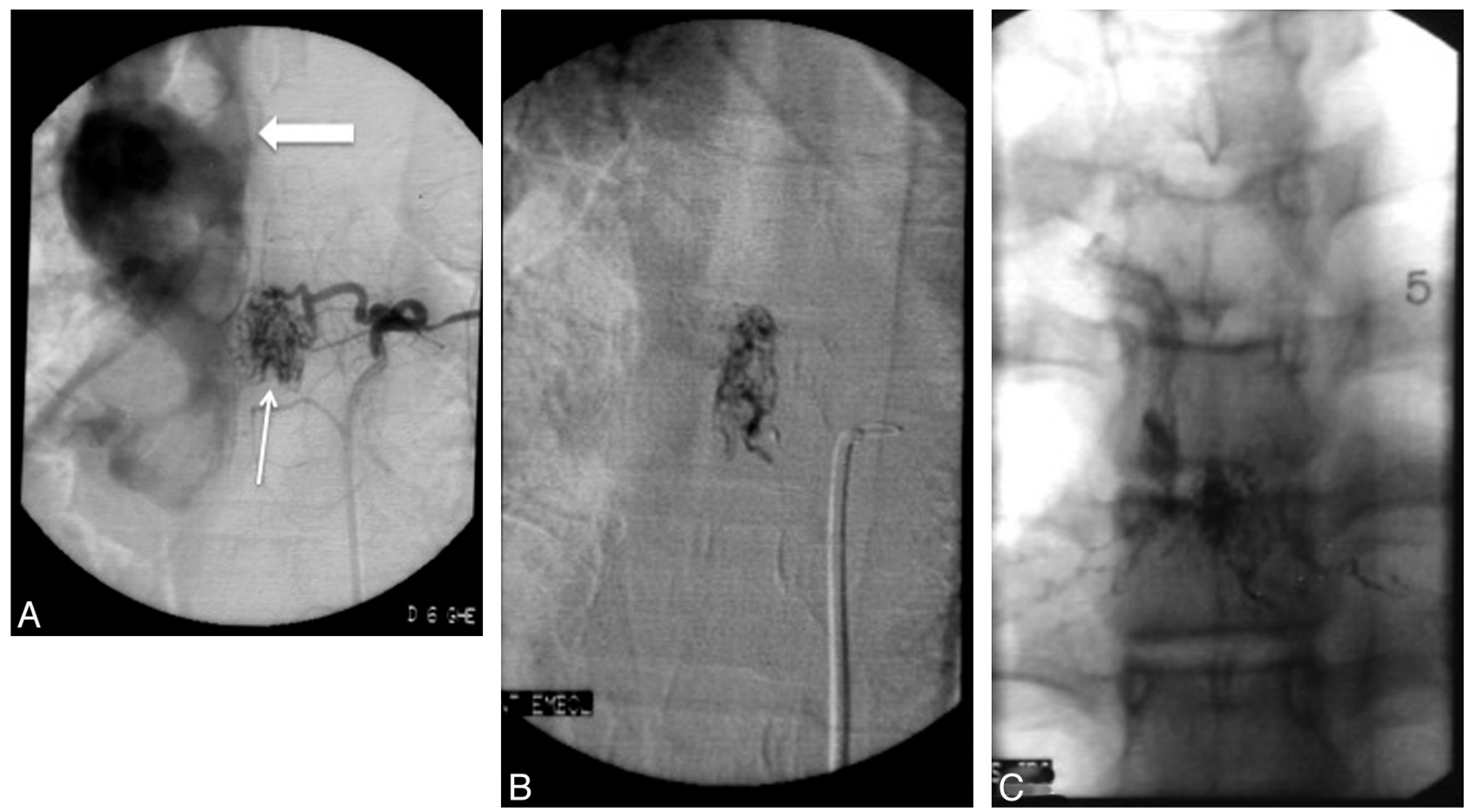

Fig 3. $A$, Epidural AVM supplied by the left $T 7$ intercostal artery (arrow). Note the venous drainage into dilated epidural veins (block arrow). $B$, Selective angiogram via a microcatheter placed into the arterial feeder shows no supply to the ASA or PSA. C, The AVM is embolized with n-BCA with the glue cast shown in the unsubtracted image.

\section{Spinal Angiography}

Despite the advances of noninvasive vascular imaging, conventional catheter spinal angiography remains the definitive test for the diagnosis and classification of spinal arteriovenous lesions due to its superior spatial resolution and image quality. Performing spinal angiography with the patient under general anesthesia improves the quality of the study because the patient remains comfortable during a potentially long study and apnea can be used to reduce motion artifacts when evaluating the thoracic spine. Angiography is performed via a $5 \mathrm{~F}$ sheath placed in the common femoral artery. An aortogram can be obtained with power injection via a pigtail high-flow catheter positioned in the descending aorta in the midthoracic level $(10 \mathrm{~mL} / \mathrm{s}$ for total volume of $35 \mathrm{~mL}$ ). The individual thoracic and lumbar segmental arteries must be selectively catheterized and evaluated. The vertebral, deep cervical, and ascending cervical arteries must be catheterized for evaluation of the cervical cord, and the internal iliac and iliolumbar arteries should be catheterized for abnormalities in the lumbosacral region. At our institution, the catheters most commonly used for catheterization of the segmental arteries are Cobra-2, VS2, and Simmons-2 (Terumo Medical, Somerset, New Jersey).

The major drawback of conventional angiography is the small risk of major complications due to its invasive nature and the use of iodinated contrast. For these reasons, only experienced interventional neuroradiologists should perform spinal angiography. Spinal angiography can be a long and tedious procedure if the lesion is not identified quickly, for it can take several hours because all arteries supplying the spine and spinal cord-from the skull base to the sacrum - may need to be studied. The degree of difficulty is higher in patients with atheromatous disease and ostial narrowing of segmental arteries. The retrograde bilateral femoral injection or bilateral femoral reflux is a useful technique that helps in identifying lesions of the lumbar or lower thoracic level. ${ }^{30}$ With bilateral $5 \mathrm{~F}$ femoral sheaths, $40 \mathrm{~mL}$ of contrast is injected into each femoral artery at a rate of $20 \mathrm{~mL} / \mathrm{s}$, resulting in opacification of the dorsal aspect of the aorta up to the T10 level. Thus, the lower thoracic and the lumbar arteries are well opacified, while the visceral arteries receive minimal contrast. If findings of the study are negative, the mid- and upper thoracic segmental arteries should be selectively catheterized, but catheterization of the lower thoracic and lumbar segmental arteries, as well as the right and left hypogastric arteries, is most likely unnecessary.

Spinal angiography should also be used to evaluate the venous drainage after injection of the artery of Adamkiewicz. In patients with severe venous hypertension and myelopathy involving the thoracolumbar area, the venous drainage is prolonged or absent. If venous hypertension is demonstrated during spinal angiography, the cause — usually a DAVF — must be found. Improvement of venous drainage after treatment is a good prognostic factor. ${ }^{31}$

\section{Endovascular Treatment}

Treatment planning for spinal vascular arteriovenous lesions is based on the hemodynamics of the lesion, location in the axial and longitudinal plane, and the angioarchitecture. Embolization is the treatment of choice for many arteriovenous anomalies. However, surgery continues to play a key role, and a multidisciplinary approach is essential. An important consideration before any intervention is a patient's preoperative neurologic status. As with all inherent disease processes of the spinal cord, postoperative function is highly related to preoperative presentation, and maximum functional results are obtained in patients treated early before advanced deterioration. Partial results can still be obtained in patients with severe neurologic impairment. 

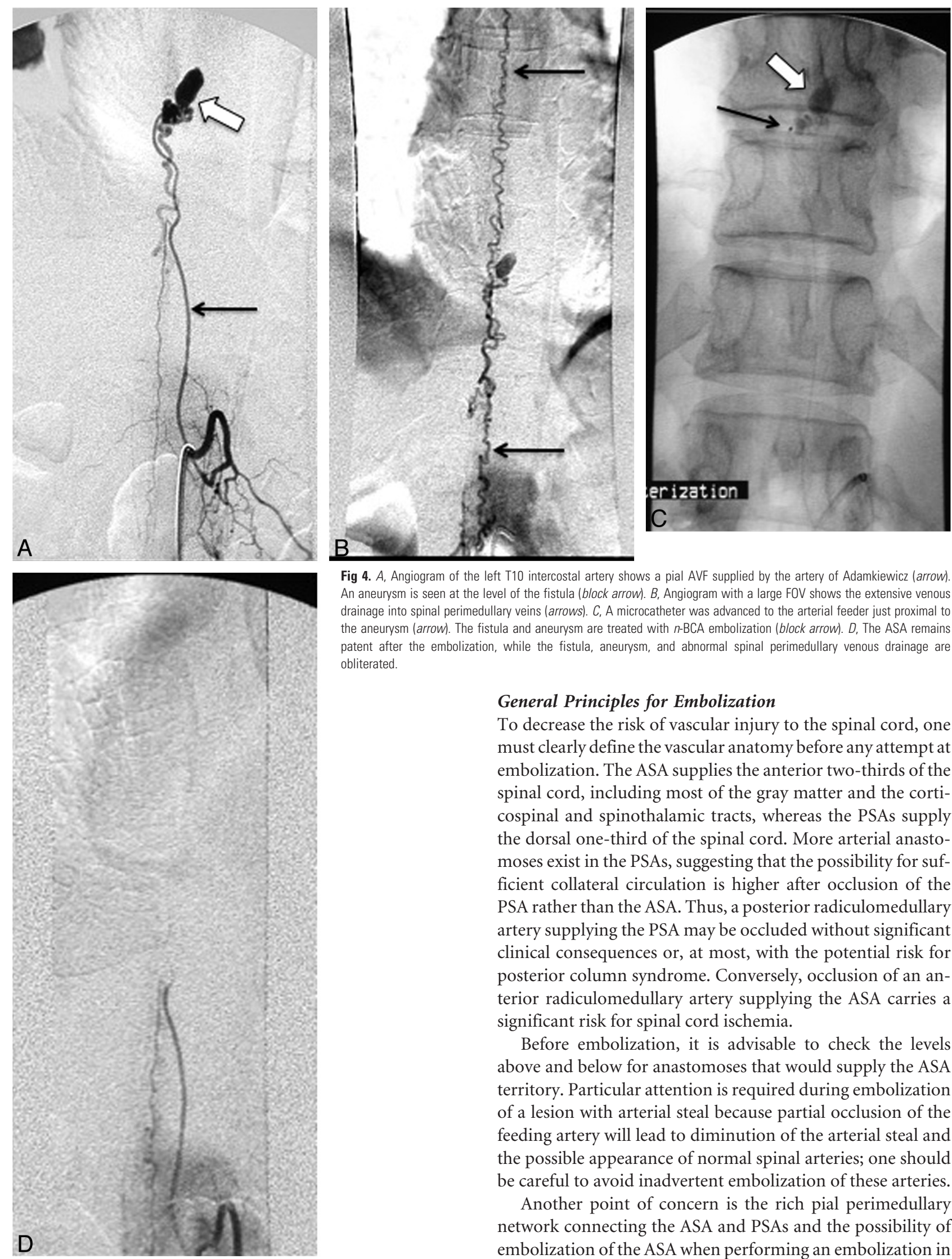

Fig 4. A, Angiogram of the left T10 intercostal artery shows a pial AVF supplied by the artery of Adamkiewicz (arrow) An aneurysm is seen at the level of the fistula (block arrow). $B$, Angiogram with a large FOV shows the extensive venous drainage into spinal perimedullary veins (arrows). C, A microcatheter was advanced to the arterial feeder just proximal to the aneurysm (arrow). The fistula and aneurysm are treated with $n$-BCA embolization (block arrow). D, The ASA remains patent after the embolization, while the fistula, aneurysm, and abnormal spinal perimedullary venous drainage are obliterated.

\section{General Principles for Embolization}

To decrease the risk of vascular injury to the spinal cord, one must clearly define the vascular anatomy before any attempt at embolization. The ASA supplies the anterior two-thirds of the spinal cord, including most of the gray matter and the corticospinal and spinothalamic tracts, whereas the PSAs supply the dorsal one-third of the spinal cord. More arterial anastomoses exist in the PSAs, suggesting that the possibility for sufficient collateral circulation is higher after occlusion of the PSA rather than the ASA. Thus, a posterior radiculomedullary artery supplying the PSA may be occluded without significant clinical consequences or, at most, with the potential risk for posterior column syndrome. Conversely, occlusion of an anterior radiculomedullary artery supplying the ASA carries a significant risk for spinal cord ischemia.

Before embolization, it is advisable to check the levels above and below for anastomoses that would supply the ASA territory. Particular attention is required during embolization of a lesion with arterial steal because partial occlusion of the feeding artery will lead to diminution of the arterial steal and the possible appearance of normal spinal arteries; one should be careful to avoid inadvertent embolization of these arteries.

Another point of concern is the rich pial perimedullary network connecting the ASA and PSAs and the possibility of embolization of the ASA when performing an embolization in a posterior radiculomedullary artery. Embolization in wedge flow carries some risks: Because of the wedge flow, there can be a change in the usual flow patterns and embolic material may reach arteries not opacified in the pre-embolization angio- 

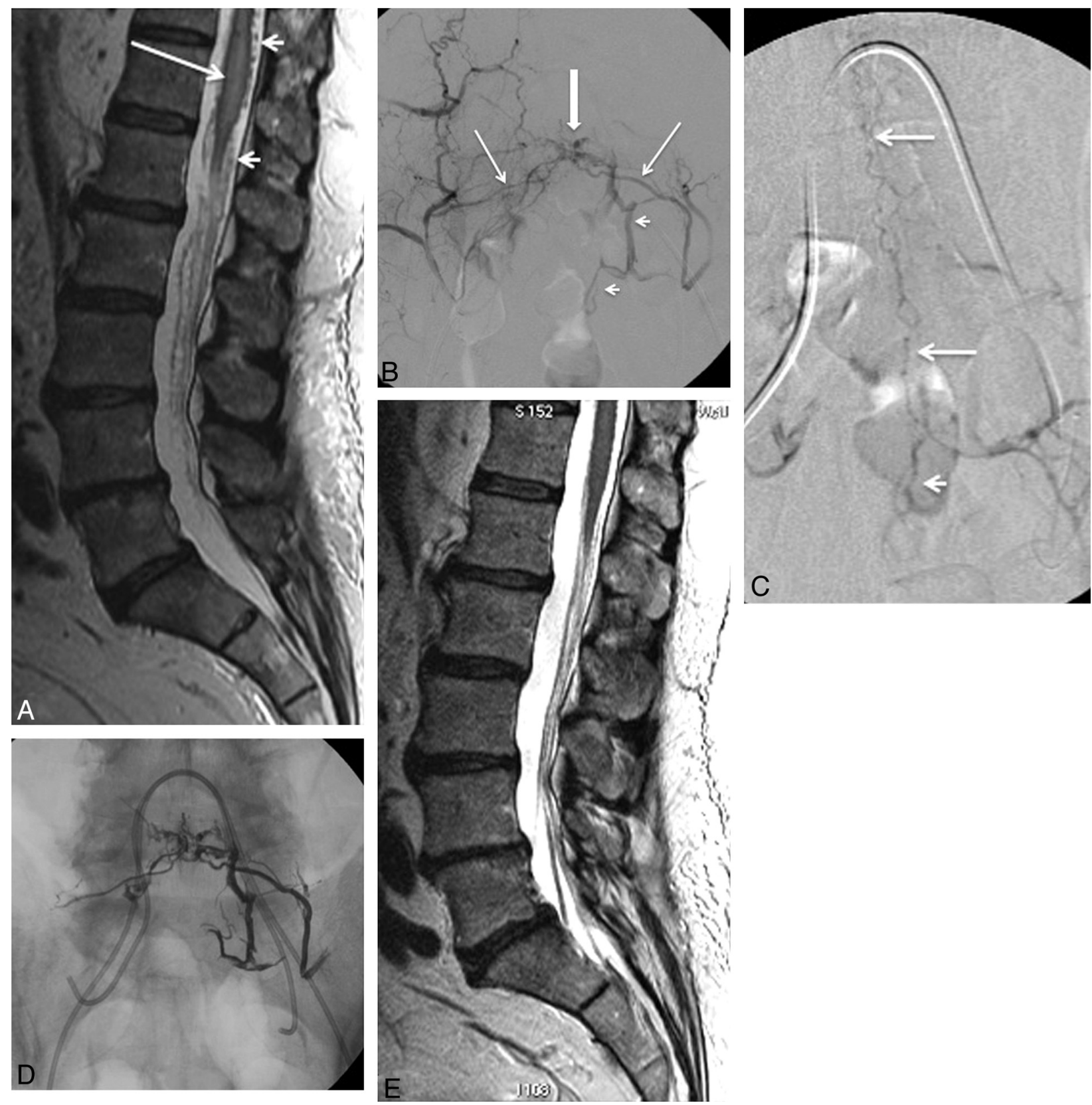

Fig 5. A, A 69-year-old man with progressive bilateral lower extremity weakness. Sagittal T2-weighted MR image shows intramedullary edema in the lower thoracic spine and the conus medullaris (arrow) with flow voids surrounding the cauda equina and conus medullaris (arrowheads), consistent with venous hypertension. $B$, Catheter angiogram shows an AVF in the sacral region (block arrow), supplied by the iliolumbar arteries bilaterally (arrows). $C$, The arteriovenous shunt drains into the sacral epidural veins (arrowheads, $B$ and $C$ ), which in turn communicate with dilated spinal veins (arrows), causing venous hypertension. D. This epidural AVF is embolized with Onyx with obliteration of the feeding arteries, the arteriovenous shunt, and epidural veins. There is no residual communication with the spinal veins. E, MR imaging of the lumbar spine obtained 7 months after the embolization shows marked improvement of the intramedullary edema and perimedullary flow voids, correlating with near-complete resolution of the patient's symptoms.

gram. Occlusion of the venous drainage of a large arteriovenous shunt also has increased risks; in an AVM, this might lead to increased pressure in the nidus and subsequent hemorrhage, whereas in an AVF, this may lead to increased venous hypertension. Last, too proximal an occlusion of an arterial feeder to an arteriovenous shunt is usually ineffective because other arterial anastomoses may subsequently be recruited to supply the shunt but may also lead to increased arterial steal because blood will now be diverted to the shunt. At the same time, the ability to access the shunt for further embolization is diminished.

\section{Lesion-Specific Technique}

Intramedullary AVM. Despite the variable classification schemes, there is generally consensus among the medical community regarding the need to treat intramedullary AVMs to alter the natural history and decrease the risk of future hemorrhage. The prognosis for untreated spinal cord AVMs is poor, with $36 \%$ of patients younger than 40 years of age developing severe impairment after 3 years of evolution. ${ }^{32}$ In the series of Hurth et al, ${ }^{33}$ $13 \%, 20 \%$, and $57 \%$ of patients had severe clinical deterioration after 5, 10, and 20 years, respectively. Thus, there is a strong indication to treat spinal cord AVMs or at least modify their natural 

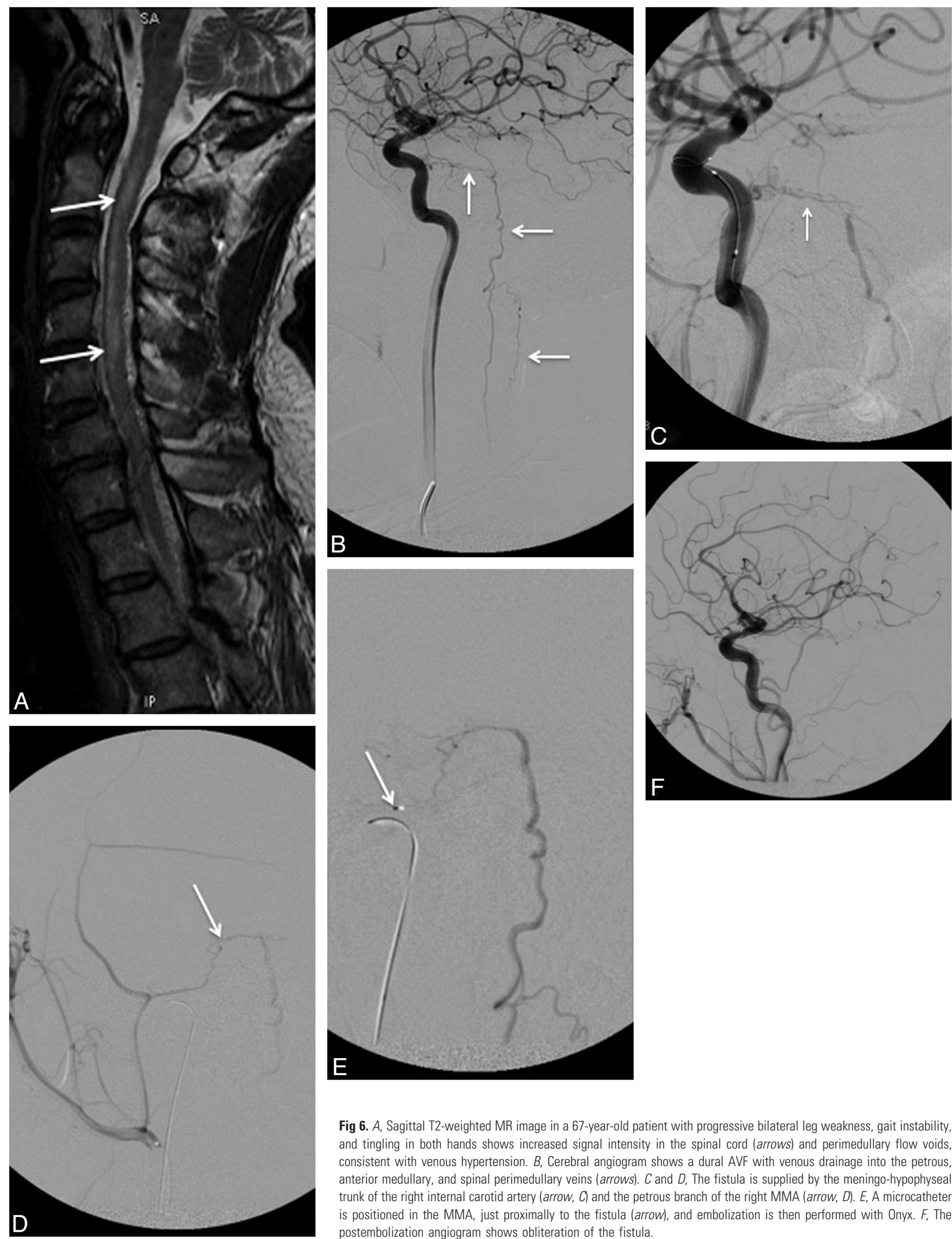

Fig 6. $A$, Sagittal T2-weighted MR image in a 67-year-old patient with progressive bilateral leg weakness, gait instability, and tingling in both hands shows increased signal intensity in the spinal cord (arrows) and perimedullary flow voids, consistent with venous hypertension. $B$, Cerebral angiogram shows a dural AVF with venous drainage into the petrous, anterior medullary, and spinal perimedullary veins (arrows). $C$ and $D$, The fistula is supplied by the meningo-hypophyseal trunk of the right internal carotid artery (arrow, $C$ ) and the petrous branch of the right MMA (arrow, D). E, A microcatheter is positioned in the MMA, just proximally to the fistula (arrow), and embolization is then performed with Onyx. F, The postembolization angiogram shows obliteration of the fistula.

history. The current available treatments include embolization, surgery, or both. Surgical obliteration can be associated with a high intraprocedural risk of neurologic injury, especially in lesions located in the anterior cord. Reports of microsurgical oblit- eration are infrequent and are predominantly limited to small case series. ${ }^{34-37}$ In patients in whom angiographic access is difficult, as in cases of an AVM with a long endovascular route or an unstable catheter position, surgery offers a viable option. A pos- 
terior superficial location makes a lesion more amenable to safe resection; however, anterior lesions can be still treated definitively with surgery, especially in the cervical region where collateral blood flow to the spinal cord can arise inferiorly. Filum terminale lesions are also amenable to surgical treatment. The basis of surgical resection of spinal AVMs, like cranial AVMs, rests in bipolar coagulation and ligation of arterial feeders to the lesion, while preserving venous drainage so as not to increase transmural pressure and the risk of intraoperative hemorrhage. Associated venous or arterial aneurysms may be removed with the nidus or shrunk with bipolar cautery.

Embolization plays an important role in the management of intramedullary spinal AVMs either as a primary treatment or as an adjunct to surgery. Even a partial embolization can improve the patient's prognosis. ${ }^{38,39}$ Modern microcatheters permit selective catheterization of the anterior or posterior arteries feeding the AVM, and the embolization can be performed with particles or liquid embolic material, each with its own advantages and disadvantages. Coils are not used in these lesions because they require relatively rigid microcatheters that cannot be safely navigated through the spinal arteries. As a result, coils can only achieve proximal embolization, which may lead to the development of collateral flow to the nidus while preventing safe access for future embolizations.

Particles have the advantage of a stepwise embolization and the ability to follow the results clinically and angiographically during the procedure, but they have the serious disadvantage of long-term recanalization. Treatment with particle embolization requires annual angiographic control and additional embolization in cases of recanalization. In a series by Biondi et $\mathrm{al}^{40}$ of thoracic AVMs embolized with particles, clinical improvement was noted in $57 \%$ of patients after the first embolization and in $63 \%$ of patients after the last embolization. Multiple embolizations were required because the AVM recanalization rate was $80 \%$. Even though embolization with particles is not a definitive treatment, it may be considered a palliative treatment because it alters the natural history and provides a good clinical outcome. The long-term results showed persistence of clinical improvement after treatment, even if the AVM recurs. This is probably explained by the fact that repeat embolizations prevent prolonged exposure of the spinal cord to the AVM.

Liquid agents have the advantage of achieving more permanent occlusion with a very low recanalization rate but with the concurrent risk of inadvertent embolization of normal perforating arteries that may not be visible on angiography. In general, a liquid agent should be used when feasible, especially when embolization is the primary or sole treatment. The liquid agent should be delivered within or as close to the nidus as possible. In a large series of spinal AVM and AVF embolizations by using $n$-BCA, ${ }^{41}$ there was good clinical outcome in $83 \%$ of patients (43\% improved, $15 \%$ remained asymptomatic, $25 \%$ stable). Embolization failed to stop the clinical evolution of the disease in $4 \%$ of patients. Permanent morbidity related to embolization was seen in $13 \%$ of patients, but only $4 \%$ of patients had severe deficits, all secondary to embolization through the ASA. Anatomic obliteration was achieved in $16 \%$ of lesions, and embolization reduced the lesion size by more than half in $86 \%$ of cases. There was no recanalization detected during follow-up (mean, 5.6 years), and recurrent hemorrhage was seen in $4 \%$ of patients, all with cervical cord AVMs reduced to $<50 \%$ of the original size. In this series, children recovered better than adults, and there was no statistically significant correlation between the degree of lesion obliteration and clinical outcome.

Onyx (ev3, Irvine, California) has also been used to treat spinal cord AVMs. In a series of 17 patients with symptomatic intramedullary AVMs (15 exclusively intramedullary and 2 with additional perimedullary components) treated exclusively by Onyx, total obliteration was achieved in 6 patients; subtotal obliteration (tiny remnant), in 5; and partial obliteration, in $5 .^{42}$ The procedure was aborted in 1 patient. Clinical improvement during follow-up (mean, 24.3 months) was noted in 14 patients, and clinical deterioration, in 3 patients, including the 1 treated surgically. There were 3 intraprocedural complications (2 extradural hematomas and $1 \mathrm{SAH}$ ) without neurologic consequences.

At our institution, embolization for intramedullary AVM is performed with the patient under general anesthesia and systemic heparin. A 5F guide catheter is placed at the ostium of the segmental artery, and a microcatheter is advanced into the radiculomedullary branch that supplies the AVM. Flowdirected microcatheters are usually more appropriate than stiffer braided microcatheters. For lesions supplied by the ASA, the microcatheter should be positioned inside or as close to the nidus as possible, preferably in a sulcal artery beyond the longitudinal axis of the ASA. This will minimize the chance of inadvertent embolization of a normal ASA branch. Similar principles are applied for lesions supplied by a feeder from the PSA, even though the consequences of accidentally occluding normal PSA branches are not as dramatic. For AVMs supplied by both ASA and PSA feeders, the PSA should be treated first because of less procedure-related risk. Embolization is usually performed with $n$-BCA mixed with ethiodized oil with 1:2 to $1: 3$ ratios, and the radiodensity of the embolic material is enhanced with tantalum powder. For high-flow shunts, a higher concentration of $n$-BCA can be used. Embolization of false and flow-related aneurysms is important to prevent recurrent hemorrhage. ${ }^{43}$ The patient is monitored in the neurologic intensive care unit for 24-48 hours. Systemic heparin is continued for 24 hours (low-dose protocol with target partial thromboplastin time of $50-60$ seconds) to prevent thrombosis of the normal spinal vessels.

\section{Intramedullary-Extramedullary AVM and Complex Angiomatosis}

Given the complex architecture of these lesions involving both intradural and extradural compartments and the fact that normal cord parenchyma is often intermingled within the actual AVM, these lesions are the most difficult to treat. Optimal therapy for these lesions has not been established, and surgery and embolization may be used alone or in combination. Achieving a complete cure in these types of vascular malformations is extremely difficult and likely associated with increased morbidity. Thus, treatment is palliative and should be targeted to relieving symptoms that may be caused by a hematoma, arterial steal, venous hypertension, or direct mass effect. Simple surgical interventions have included ligation of a feeding artery, ${ }^{5}$ and decompressive laminectomy; however, these modalities are incomplete at best and offer controversial ben- 
efit. Although rare, there have been case reports in the literature of complete surgical cure by using combined angiographic embolization and extensive surgical resection. ${ }^{6-8}$ Embolization can be performed with particles if used preoperatively.

\section{Pial AVFs}

Pial AVFs represent a heterogeneous group of lesions, and the therapeutic approach depends largely on the individual lesion angioarchitecture. Treatment must be performed early, aimed at surgical or endovascular obliteration of the fistula at the point of arteriovenous connection. Embolization can also be used as an adjunct to surgery. ${ }^{44}$ Regardless of treatment, complete and permanent occlusion of the fistula is the only way to prevent long-term recurrence. Thus, liquid embolic materials are the agents of choice, and PVA particles should be used only for presurgical embolization. In small AVFs, superselective catheterization and placement of the microcatheter inside the fistula for effective embolization is difficult because the arterial feeder is a distal branch of a thin ASA. ${ }^{45}$ For large AVFs, embolization is seldom efficient because of the multiple feeding arteries, some of which are transmedullary or perimedullary branches that cannot be safely catheterized. Embolization has been reported in selected cases. Oran et $\mathrm{al}^{46}$ reported successful glue embolization in 4/5 patients with small AVFs, followed by clinical improvement in 3 patients. Cho et $\mathrm{al}^{47}$ reported successful complete embolization in $3 / 5$ patients (partial embolization in 1 patient) with small AVFs and $0 / 2$ patients (partial embolization in 2 patients) with large AVFs. Clinical improvement or stability was seen in $2 / 4$ patients with small AVFs ( 1 worsened) and in one-half of patients with large AVF (1 worsened). One patient treated with PVA demonstrated recurrent fistula 3 months after the embolization. On the other hand, microsurgical treatment plays a curative role, especially in lesions located on the dorsal/dorsolateral cord.

The goal of surgical treatment is to interrupt the connection between the arterial and venous system while preserving the ASA branches. Superselective catheterization of the arterial feeder is more feasible in giant AVFs due to their increased diameter and the high flow through the shunt. The massively dilated draining veins increase the risk of intraoperative hemorrhage and the difficulty of surgical treatment. Thus, embolization is the treatment of choice in these lesions. The major challenge of embolization is placing the embolization material in the proper position without venous migration. Ricolfi et $\mathrm{al}^{16}$ reported their results of endovascular treatment of 12 patients with giant AVFs of the spinal cord, by using balloons or particles. Treatment with nondetachable balloons was curative in 5/6 patients; embolization failed secondary to spasm in 1 patient. Treatment with detachable balloons was curative in 3 patients; partial embolization was achieved in 1 patient. In 1 patient who was treated with a detachable balloon, the balloon migrated into the venous site causing clinical deterioration. The fistula was completely occluded in 2 patients treated with gelatin sponge particles. Clinical improvement was seen in $6 / 10$ patients with complete occlusion of the fistula. In a series of 35 patients with pial AVFs, Mourier et $\mathrm{al}^{5}$ reported their results in 22 giant AVFs treated with detachable balloons. Complete occlusion of the fistula was achieved in 15 patients, all with clinical improvement posttreatment. Of 6 patients with partial occlusion, 4 remained unchanged and 2 worsened clinically posttreatment. There was 1 periprocedural death.

Detachable and nondetachable balloons are not available in the United States today, and the use of particles alone is not indicated because the particles may pass through the shunt into the venous circulation where they may cause inadvertent thrombosis or pulmonary embolism. Instead, coils alone or combined with liquid embolic materials should be the agents of choice. In giant AVFs, coils can be placed in the fistula to act as a frame for the liquid embolic material and prevent migration through the high-flow shunt into the venous side. This technique requires the use of a microcatheter with an inner diameter large enough to allow deployment of coils. The embolization should occur at the fistula and proximal draining veins to prevent development of inaccessible collateral feeders and recanalization of the fistula. Progressive retrograde thrombosis of the veins draining the fistula may result in transient worsening of symptoms. This can be prevented by administration of systemic heparin for 24-48 hours postembolization.

\section{Conclusions}

This article represents an overview of spinal vascular lesions with reference to the indications, contraindications, and techniques of endovascular treatment. While knowledge of the vascular anatomy and the pathophysiology of each spinal vascular lesion is necessary to achieve safe and effective treatment, a multidisciplinary approach with endovascular and surgical specialists working closely together is paramount to achieve the best possible results.

\section{References}

1. Krings T, Geibprasert S. Spinal dural arteriovenous fistulas. AJNR Am J Neuroradiol 2009;30:639-48

2. Krings T, Mull M, Gilsbach JM, et al. Spinal vascular malformations. Eur Radio 2005;15:267-78

3. Barnwell SL, Dowd CF, Davis RL, et al. Cryptic vascular malformations of the spinal cord: diagnosis by magnetic resonance imaging and outcome of surgery. J Neurosurg 1990;72:403-07

4. Rosenblum B, Oldfield EH, Doppman JL, et al. Spinal arteriovenous malformations: a comparison of dural arteriovenous fistulas and intradural AVM's in 81 patients. J Neurosurg 1987;67:795-802

5. Mourier KL, Gobin YP, George B, et al. Intradural perimedullary arteriovenous fistulae: results of surgical and endovascular treatment in a series of 35 cases. Neurosurgery 1993;32:885-91; discussion 891

6. Biondi A, Merland JJ, Hodes JE, et al. Aneurysms of spinal arteries associated with intramedullary arteriovenous malformations. I. Angiographic and clinical aspects. AJNR Am J Neuroradiol 1992;13:913-22

7. Di Chiro G, Doppman JL. Endocranial drainage of spinal cord veins. Radiology 1970;95:555-60

8. Hurst RW, Kenyon LC, Lavi E, et al. Spinal dural arteriovenous fistula: the pathology of venous hypertensive myelopathy. Neurology 1995;45:1309-13

9. Jellema K, Tijssen CC, van Gijn J. Spinal dural arteriovenous fistulas: a congestive myelopathy that initially mimics a peripheral nerve disorder. Brain 2006;129:3150-64

10. Merland JJ, Riche MC, Chiras J. Intraspinal extramedullary arteriovenous fistulae draining into the medullary veins. J Neuroradiol 1980;7:271-320

11. Djindjian $M$, Djindjian $R$, Hurth $M$, et al. Steal phenomena in spinal arteriovenous malformations. J Neuroradiol 1978;5:187-201

12. el Mahdi MA, Rudwan MA, Khaffaji SM, et al. A giant spinal aneurysm with cord and root compression. J Neurol Neurosurg Psychiatry 1989;52:532-35

13. Spetzler RF, Detwiler PW, Riina HA, et al. Modified classification of spinal cord vascular lesions. J Neurosurg 2002;96:145-56

14. Gueguen B, Merland JJ, Riche MC, et al. Vascular malformations of the spinal cord: intrathecal perimedullary arteriovenous fistulas fed by medullary arteries. Neurology 1987;37:969-79

15. Nakstad PH, Hald JK, Bakke SJ. Multiple spinal arteriovenous fistulas in 
Klippel-Trenaunay-Weber syndrome treated with platinum fibre coils. $\mathrm{Neu}$ roradiology 1993;35:163-65

16. Ricolfi F, Gobin PY, Aymard A, et al. Giant perimedullary arteriovenous fistulas of the spine: clinical and radiologic features and endovascular treatment. AJNR Am J Neuroradiol 1997;18:677-87

17. Rodesch G, Hurth M, Alvarez H, et al. Angio-architecture of spinal cord arteriovenous shunts at presentation: clinical correlations in adults and children-the Bicetre experience on 155 consecutive patients seen between 19811999. Acta Neurochir (Wien) 2004;146:217-26; discussion 226-27. Epub 2004 Feb 23

18. Arnaud O, Bille F, Pouget J, et al. Epidural arteriovenous fistula with perimedullary venous drainage: case report. Neuroradiology 1994;36:490-91

19. Clarke MJ, Patrick TA, White JB, et al. Spinal extradural arteriovenous malformations with parenchymal drainage: venous drainage variability and implications in clinical manifestations. Neurosurg Focus 2009;26:E5

20. Weingrad DN, Doppman JL, Chretien PB, et al. Paraplegia due to posttraumatic pelvic arteriovenous fistula treated by surgery and embolization: case report. J Neurosurg 1979;50:805-10

21. Kawabori M, Hida K, Yano S, et al. Cervical epidural arteriovenous fistula with radiculopathy mimicking cervical spondylosis. Neurol Med Chir (Tokyo) 2009;49:108-13

22. Willinsky $\mathrm{R}$, terBrugge $\mathrm{K}$, Lasjaunias $\mathrm{P}$, et al. The variable presentations of craniocervical and cervical dural arteriovenous malformations. Surg Neurol 1990;34:118-23

23. Szajner M, Weill A, Piotin M, et al. Endovascular treatment of a cervical paraspinal arteriovenous malformation via arterial and venous approaches. $A J N R$ Am I Neuroradiol 1999;20:1097-99

24. Willinsky R, terBrugge $\mathrm{K}$, Montanera W, et al. Spinal epidural arteriovenous fistulas: arterial and venous approaches to embolization. AJNR Am J Neuroradiol 1993;14:812-17

25. Djindjian M, Djindjian R, Rey A, et al. Intradural extramedullary spinal arterio-venous malformations fed by the anterior spinal artery. Surg Neurol 1977;8:85-93

26. Djindjian R, Hurth M, Houdart R. Medullary angiomas, segmentary or generalized vascular dysplasias and phakomatoses [in French]. Rev Neurol (Paris) 1969;121:109-11

27. Djindjian R, Hurth M, Houdart R. Spinal angiomas, segmentary vascular dysplasia and phacomatosis [in French]. Rev Neurol (Paris) 1971;124:121-42

28. Houdart E, Gobin YP, Casasco A, et al. A proposed angiographic classification of intracranial arteriovenous fistulae and malformations. Neuroradiology 1993;35:381-85

29. Ricolfi F, Manelfe C, Meder JF, et al. Intracranial dural arteriovenous fistulae with perimedullary venous drainage: anatomical, clinical and therapeutic considerations. Neuroradiology 1999;41:803-12

30. Melki JP, Riche MC, Reizine D, et al. Simultaneous bifemoral retrograde arteriography under pressure: first stage in angiographic exploration of the spine and spinal cord [in English, French]. J Neuroradiol 1986;13:62-70
31. Gobin YP, Rogopoulos A, Aymard A, et al. Endovascular treatment of intracranial dural arteriovenous fistulas with spinal perimedullary venous drainage. J Neurosurg 1992;77:718-23

32. Aminoff MJ, Logue $V$. The prognosis of patients with spinal vascular malformations. Brain 1974;97:211-18

33. Hurth M, Houdart R, Djindjian R, et al. Arteriovenous malformations of the spinal cord: clinical, anatomical and therapeutic consideration: a series of 150 cases. Progr Neurol Surg 1978;9:238-66

34. Bostrom A, Krings T, Hans FJ, et al. Spinal glomus-type arteriovenous malformations: microsurgical treatment in $\mathbf{2 0}$ cases. J Neurosurg Spine 2009, 10:423-29

35. Connolly ES Jr, Zubay GP, McCormick PC, et al. The posterior approach to a series of glomus (type II) intramedullary spinal cord arteriovenous malformations. Neurosurgery 1998;42:774-85, discussion 785-86

36. Tai PA, Tu YK, Liu HM. Surgical treatment of spinal arteriovenous malformations: vascular anatomy and surgical outcome. J Formos Med Assoc 2001;100:389-96

37. Zozulya YP, Slin'ko EI, Al-Qashqish II. Spinal arteriovenous malformations: new classification and surgical treatment. Neurosurg Focus 2006;20:E7

38. Djindjian R, Cophignon J, Rey A, et al. Superselective arteriographic embolization by the femoral route in neuroradiology: study of $\mathbf{5 0}$ cases. II. Embolization in vertebromedullary pathology. Neuroradiology 1973;6:132-42

39. Doppman JL, Di Chiro G, Ommaya A. Obliteration of spinal-cord arteriovenous malformation by percutaneous embolisation. Lancet 1968;1:477

40. Biondi A, Merland JJ, Reizine D, et al. Embolization with particles in thoracic intramedullary arteriovenous malformations: long-term angiographic and clinical results. Radiology 1990;177:651-58

41. Rodesch G, Hurth M, Alvarez H, et al. Embolization of spinal cord arteriovenous shunts: morphological and clinical follow-up and results-review of 69 consecutive cases. Neurosurgery 2003;53:40-49; discussion 49-50

42. Corkill RA, Mitsos AP, Molyneux AJ. Embolization of spinal intramedullary arteriovenous malformations using the liquid embolic agent, Onyx: a singlecenter experience in a series of 17 patients. J Neurosurg Spine 2007;7:478-85

43. Konan AV, Raymond J, Roy D. Transarterial embolization of aneurysms associated with spinal cord arteriovenous malformations: report of four cases. J Neurosurg 1999;90:148-54

44. Hida K, Iwasaki Y, Goto K, et al. Results of the surgical treatment of perimedullary arteriovenous fistulas with special reference to embolization. J Neuro surg 1999;90:198-205

45. Riche MC, Melki JP, Merland JJ. Embolization of spinal cord vascular malformations via the anterior spinal artery. AJNR Am J Neuroradiol 1983;4:378-8

46. Oran I, Parildar M, Derbent A. Treatment of slow-flow (type I) perimedullary spinal arteriovenous fistulas with special reference to embolization. AJNR Am J Neuroradiol 2005;26:2582-86

47. Cho KT, Lee DY, Chung CK, et al. Treatment of spinal cord perimedullary arteriovenous fistula: embolization versus surgery. Neurosurgery 2005;56: 232-41, discussion 232-41 